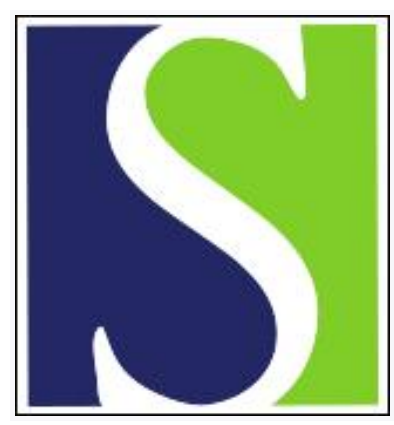

Scand J Work Environ Health 1979;5(3):205-210

https://doi.org/10.5271/sjweh.3094

Issue date: Sep 1979

Clinical and ergonomic factors in prolonged shoulder pain among industrial workers

by Bjelle A, Hagberg M, Michaelsson G

Affiliation: Department of Rheumatology, University of Umeå, S-901 85 Umeå, Sweden.

Key terms: arthritis; clinical factor; ergonomic factor; ergonomics; industrial worker; occupational health; pain; prolonged shoulder pain; shoulder; shoulder pain

This article in PubMed: www.ncbi.nlm.nih.gov/pubmed/20120568

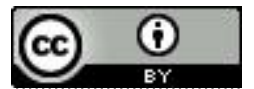




\title{
Clinical and ergonomic factors in prolonged shoulder pain among industrial workers
}

\author{
by ANDERS BJELLE, M.D., ${ }^{1}$ MATS HAGBERG, M. D., ${ }^{2}$ and \\ GUNNAR MICHAELSSON, M.D. ${ }^{3}$
}

\begin{abstract}
BJELLE, A., HAGBERG, M. and MICHAELSSON, G. Clinical and ergonomic factors in prolonged shoulder pain among industrial workers. Scand. j. work environ. $\&$ health 5 (1979) 205-210. Twenty male patients who were attending an occupational health care center because of prolonged (more than three months) shoulder pain were subjected to extensive rheumatological and laboratory examinations. Ergonomic and anthropometric data were compared with those of matched referents. Inflammatory rheumatic diseases were diagnosed for three patients (rheumatoid arthritis for one and reactive arthritis to urinary infections for two). No definite diagnosis was possible with regard to the other 17 patients. Their ages were significantly higher than the mean age of workers at their respective factories and that of industrial workers in Sweden. The anthropometric measurements for these patients did not differ from those of the matched referents or from other Swedish males of the same age. Shoulder load, estimated as work with hands at or above acromion height, was significantly heavier among the patient group than among the referents. Neither the evaluated physical load of their current work nor previous hard work was found to be a significant factor. A follow-up two years later showed a definite deterioration, the majority being on pension or still on sick leave.
\end{abstract}

Key words: arthritis, ergonomics, industrial workers, occupational health, shoulder.

Shoulder pain is common in the general population (1) and a frequent problem among industrial workers $(2,11)$. A variety of etiological factors have been reported $(5,6,7,14,17)$, including the influence of personality disturbances $(6,18)$. However, a definite cause is rarely revealed in a medical examination of patients with

1 Department of Rheumatology, University of Umeå, Umeå, Sweden.

2 Work Physiology Division, National Board of Occupational Safety and Health, Umeå, Sweden.

3 Industrial Health Care Center, Volvo Umeverken, Umeå, Sweden.

Reprint requests to: Dr. Anders Bjelle, Department of Rheumatology, University of Umeå, S-901 85 Umeå, Sweden. shoulder pain (16), and the classification of shoulder disorders is unsatisfactory (16).

At a local occupational health care center, almost $40 \%$ of the visits are the result of nontraumatic musculoskeletal disorders (fig. 1). Next to low back pain, neck and shoulder pain are the most common, in some industries accounting for half of the rheumatic diagnoses. A program for the study of shoulder pain was initiated in collaboration with the local rheumatology unit. This report presents the clinical and ergonomic findings over a period of one year for 20 consecutive patients with prolonged shoulder pain resistant to conventional medical and/or physiotherapy. 


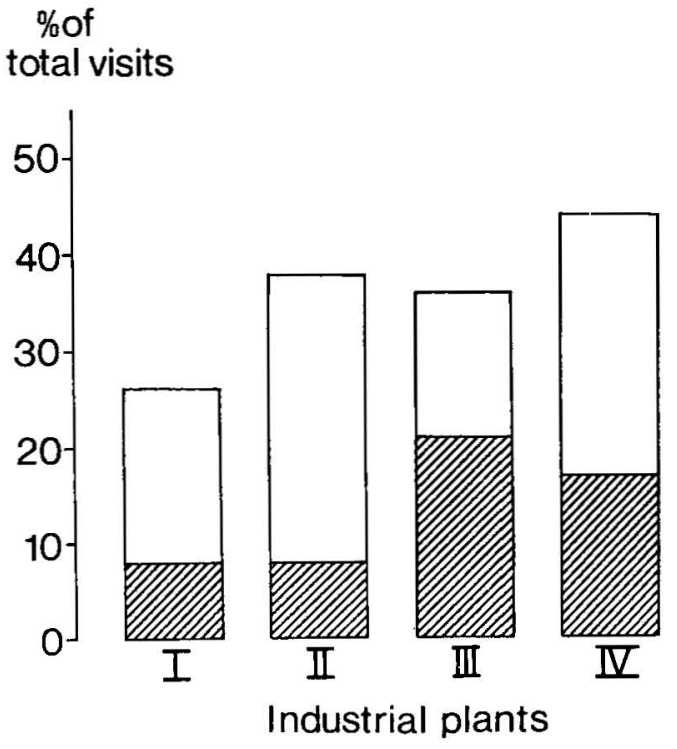

Fig. 1. Distribution of all nontraumatic musculoskeletal disorders (Chapter XIII of the International Classification of Diseases) diagnosed for patients from four different industrial workplaces (I-IV); the patients visited respective occupational health care centers and were examined by the same doctor in 1977. Values are given as percentages of total visits from the respective industrial plants. ( $\mathbb{Z}$ neck-shoulder complaints, $\square$ nontraumatic musculoskeletal disorders)

\section{MATERIAL AND METHODS}

Twenty consecutive male patients admitted to the health care center from six major industries in Umeå, Sweden, and suffering from pain over a period of more than three months in one or both shoulders were included in the study. Usual attempts to treat the complaints with analgesics, nonsteroidal antiinflammatory drugs and physiotherapy had been of little or no benefit.

The workplaces from which the patients came were three machine shops, two pulpmills and a sawmill, with a total of 2,500 employees. The same physician, serving at three different health care centers, sees the employees of all six workplaces. Each of the three health care centers is staffed by one or two nurses, and one of them also has a physiotherapist.

\section{Compared series}

For each patient two matched referents were selected from manual workers in the employment records according to age $( \pm 1$ year), sex and workshop. For the comparison of anthropometric data, a sample of Swedish industrial workers (9) and the referents were used.

\section{Medical examination}

At the health care center the patients had a physical examination which included measurements of grip strength with a medium-sized ball vigorimeter. Routine blood tests were carried out for the determination of sedimentation rates and hemoglobin. Urine samples were tested for protein and sugar.

The patients were referred to the outpatient department of the rheumatology unit. Clinical and extensive routine laboratory examinations such as serology and the determination of muscle enzymes were performed. Standard radiographs were taken of the cervical spine, shoulder joints, and other joints or parts of the spine according to symptoms or physical findings. Clinical electromyographs and, for the majority of the patients (15 cases), open muscle biopsies were performed for routine histopathological examination.

\section{Ergonomic evaluation}

The degree of physical work load (requirements of the task) for each patient and referent was assessed by the health care center in collaboration with the individuals. The physician had personal knowledge of the work involved in each case. The following three classes were chosen:

1. Light physical work load: work performed in a sitting position or work performed while standing without heavy $(>10 \mathrm{~kg}$ ) weight lifting or carrying.

2. Heavy physical work load: work performed while standing, weight lifting and carrying occurring in the normal work cycle three to eight times during the day (once or less an hour). 
3. Very heavy physical work load: work performed while standing, repetitive (more than once an hour) weight lifting and carrying occurring during the day.

So that the specific load on the shoulders could be evaluated, the work height for the hands was determined $(12,15,18)$ through the combined efforts of the patient or referent and the physician. The following three classes were chosen:

1. Work performed in the work cycle with the hands below shoulder or acromion height.

2. Work performed in the work cycle with the hands at or above acromion height three to eight times during the day (less than once an hour and for a duration of more than $1 \mathrm{~min}$ ).

3. Work performed in the work cycle with the hands at or above acromion height at least eight times a day (at least once an hour and for a duration of more than 1 $\min$ ).

\section{RESULTS}

Inflammatory rheumatic diseases (3 cases)

Three patients revealed inflammatory rheumatoid diseases which had not been previously diagnosed. One patient had rheumatoid arthritis, and the other two suffered from reactive arthritis to urinary infections (Reiter's syndrome). Since their clinical pictures were somewhat difficult to recognize, particularly when conventional signs of inflammation were lacking, short clinical descriptions follow.

Case $S L$ (a 60-year-old man with periods of diffuse shoulder-neck pain for 15 years). During the last two years case SL was incapable of work due to swelling and pain in the finger joints, stiffness of joints for $2 \mathrm{~h}$ in the morning, and finally pain on movement and weakness in the shoulder muscles. On examination, a slight symmetric swelling of the finger joints was observed. He had a decreased range of movement, pain on motion, and an increased skin temperature over the shoulder joints. A pronounced weakness in shoulder muscles and hand grip and hypotrophy of the shoulder girdle muscles were observed.

The patient's routine blood tests were within the normal range, but the rheuma-factor titer was highly elevated (Waaler's test $1 / 1280$ ). His electromyograph showed myopathy of the deltoid and trapezius muscles, while the routine muscle biopsy was normal. Radiographs of the shoulder area showed signs of moderate osteoarthritis, but no erosions were observed in the shoulder or finger joints. With anti-inflammatory treatment, the patient has been able to continue work, now adjusted to his shoulderload capacity. He still has periodic pain in the shoulder-neck area, as he had before he developed symptoms of rheumatoid arthritis.

Case JH (a 29-year-old man with recidivating prostatitis over a period of ten years). During the last two years case JH had experienced lowback pain and pain in the shoulder-neck radiating into the arms. At examination his sternoclavicular joints were tender and swollen. $\mathrm{He}$ had tenderness over the sternum and some sternoclavicular junctions, diffuse tenderness around the glenohumeral capsule of the shoulders, and radial epicondylitis of both elbows. His left knee joint was warm and swollen, and he had signs of conjunctivitis and prostatitis. His routine laboratory tests and radiographs were all negative. He was HLA-B 27 positive. He was not completely symptom-free in his work, despite treatment, and he started retraining by going back to school to obtain a nonmanual job.

Case GH (a 31-year-old man with symptoms of low-back pain after a period of diarrhea with fever three years earlier). Case GH noticed arthralgia of the hip, knee, and shoulder joints on the right side and symptoms of urethritis simultaneously. On examination the patient had diffuse pain around the capsule of the right glenohumeral joint and signs of prostatitis. His routine laboratory tests and radiographs were normal. He was HLA-B 27 positive. With antiinflammatory treatment he was symptom-free and could return to work.

\section{Noninflammatory rheumatic diseases (17 cases)}

Clinical findings. For the 17 patients with no inflammatory rheumatic diseases, the mean age was 53.4 years. This value was significantly $(p<0.05)$ higher than the mean age (37.6 years) of other workers from these workplaces. The mean duration of symptoms from onset to referral to the Department of Rheumatology was 2.2 years. The mean stature and mean body weight of the patient group did not differ 
Table 1. Total work load in previous and current work of 17 patients with chronic (noninflammatory) shoulder complaints and for 34 referents.

\begin{tabular}{|c|c|c|c|c|c|}
\hline \multirow[b]{2}{*}{ Group } & \multicolumn{2}{|c|}{ Previous work } & \multicolumn{2}{|c|}{ Current work } & \multirow{2}{*}{$\begin{array}{c}\text { Total } \\
\text { number }\end{array}$} \\
\hline & $\begin{array}{l}\text { Light or } \\
\text { heavy }\end{array}$ & $\begin{array}{c}\text { Very } \\
\text { heavy }\end{array}$ & $\begin{array}{c}\text { Light or } \\
\text { heavy }\end{array}$ & $\begin{array}{c}\text { Very } \\
\text { heavy }\end{array}$ & \\
\hline Patients & 4 & 13 & 10 & 7 & 17 \\
\hline Referents & 10 & 24 & 23 & 11 & 34 \\
\hline
\end{tabular}

from those of a sample of Swedish industrial workers (9) or from those of the referents. Thirteen patients had an impaired range of active shoulder movement due to pain, nine of these patients experiencing it on both sides and the other four in the right shoulder only. Signs of bicipital tendinitis and/or supraspinate tendinitis was found in 12 patients. Tenderness of the cervical spine or an impaired range of cervical movement was found in 15 of the 17 patients. The mean grip strength of the right hand was significantly lower $(p<0.05)$ in the patient group in a comparison with the referents.

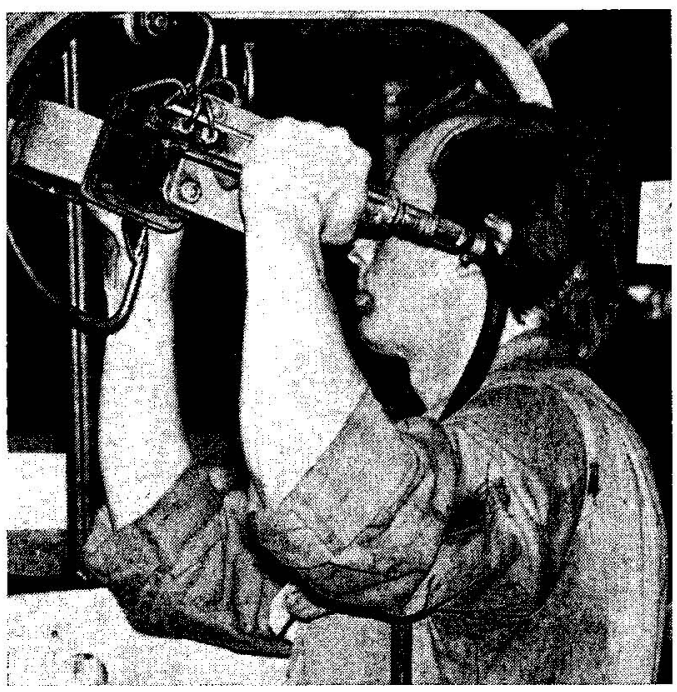

Fig. 2. Illustration of a typical work position, with hands above acromion height, resulting in a heavy load on the shoulders.
Laboratory findings. By means of standard radiographs of the shoulder joints, sclerosis and/or osteophytes were found in five glenohumeral joints. Signs of reduced cartilage thickness were found in one of these patients. Radiographs of the cervical spine revealed degnerative changes (osteophytic deposits on the margins of the vertebral bodies and/or narrowing of the interverterbral spaces) in 15 of the 17 patients. Electromyographic examinations and nerve conduction velocity measurements were performed on 15 patients, and an open muscle biopsy on 11 patients. Myopathic signs were not found in either the electrophysiological examinations or in the routine pathology examinations of the muscle biopsies. Routine laboratory tests, including lactic dehydrogenase, sedimentation rates and serum electrophoresis, were within the normal range for all the patients. Muscle enzymes (creatine phosphokinase and/or aldolase) were elevated in six patients.

Ergonomic evaluation. The physical work load of previous employment (table 1) was assessed as having been very heavy in the majority of the patients. This finding was however not significantly different from that of the referents. The present work situation was assessed as being very heavy for less than half of the patients (table 1), but it did not significantly differ from that of the referents. The work load of the shoulders in the current work situation (fig. 2), judged as work performed with the hands above acromion height (table 2), was significantly heavier $(p<0.05)$ for the patients than for the referents. 
Table 2. Work load on the shoulders, measured as work height of the hands at or above acromion height, of the same 17 patients and 34 referents presented in table 1 .

\begin{tabular}{lccc}
\hline Group & $\begin{array}{c}\text { Work performed } \\
\text { below acromion } \\
\text { height }\end{array}$ & $\begin{array}{c}\text { Work performed } \\
\text { at or above } \\
\text { acromion height }\end{array}$ & $\begin{array}{c}\text { Total } \\
\text { number }\end{array}$ \\
\hline Patients & 6 & 11 & 17 \\
Referents & 29 & 5 & 34 \\
\hline
\end{tabular}

Prognosis. All 17 patients had work disabilities for more than one month after the visit at the rheumatology department where the majority of the patients were treated with local injections of corticosteroids. The study does not however allow conclusions to be drawn regarding the efficacy of the treatment.

A follow-up two years after the first examination showed that only eight patients were working in the same or lessheavy types of work, although seven of these patients still had slight shoulder complaints. Three patients were retraining for transfer to easier work, four were on sick leave, and five patients had been given disability pensions.

\section{DISCUSSION}

Inflammatory rheumatic diseases have been rare findings in earlier reports on chronic shoulder complaints $(5,6,7,11,14$, 17, 19). These diseases are sometimes difficult to recognize when symptoms are predominantly extra-articular and laboratory findings of inflammation are absent. Muscular symptoms are more frequent in arthritis including rheumatoid arthritis, than was previously recognized (4), and in reactive arthritis severe extra-articular symptoms are common (3). The latter diagnosis represents a minor but important part of the present material since such patients are young and require medical treatment and, often, retraining for less heavy work.

The older age of the chronic patients with "noninflammatory" shoulder complaints is in accordance with the findings of other studies $(11,13,19)$. Several of the patients seemed older than their years, but no satisfactory method is currently available for the further investigation of this impression. Hard work from childhood is traditionally thought to predispose people to early aging and to produce symptoms in the musculoskeletal system. This assumption was not however confirmed by the findings of the present study of shoulder complaints. The lack of correlation in this study between shoulder complaints and total load in the present work situation has been reported earlier (11).

The increased load on shoulder muscles during work with the hands at or above acromion height has been demonstrated by direct measurements $(8,10,12,15)$. The present study has shown that a careful case history can disclose a shoulder load of clinical significance. In elderly workers with less flexible connective tissues and in individuals with musculoskeletal diseases, correction of the work height of the hands seems essential (fig. 2). The difference in the frequency of shoulder symptoms between workplaces I-II and IIIIV might be explained by the same factor since I and II are processing plants where work performed at or above acromion height is unusual. In workplaces III and IV (fig. 1), on the other hand, assembly work at or above acromion height is frequent. Additional studies to elucidate ergonomic factors in acute shoulder complaints and differences between work situations are in progress.

The case histories and clinical examinations were very important for the determination of the three cases of inflammatory rheumatoid diseases, while little was added 
by the radiological and laboratory investigations. The finding of $80 \%$ degenerative changes by means of radiography of the cervical spine is consistent with an earlier investigation of Swedish males between 50 and 60 years (11), and the radiological osteoarthritis of the glenohumeral joints found in four patients did not correlate with symptoms or to prognosis. The standard electromyograph was positive only in the case of rheumatoid myopathy, and routine muscle biopsies were of no value despite predominant muscle wasting in a number of patients. Positive rheumatoid factor was found in one patient only, but it was not conclusive in itself for the diagnosis. Muscle enzyme blood levels were of no diagnostic aid. Clinically the 17 patients with noninflammatory rheumatic disease would best suit the diagnosis "degenerative tendinitis" used in some textbooks as opposed to "capsulitis" or "frozen shoulder" (6).

The present study has shown some factors that should be routinely screened in cases of chronic shoulder complaints. First, inflammatory rheumatoid diseases must be recognized. They may exhibit predominantly extra-articular symptoms and lack conventional laboratory signs of inflammation. The case history and a careful examination will produce the diagnosis, and the disease should be suspected particularly in young patients. Second, the work height of the hands in relation to the shoulders determines the work load on the shoulders. This is a causative factor and should be corrected or preferably prevented. Finally, the shoulders are less resistant to load with increasing age, and the prognosis for patients over 50 years of age with prolonged shoulder pain is poor. Thus ergonomic factors are especially important for elderly workers.

\section{REFERENCES}

1. ALLANDER, E. Prevalence, incidence and remission rates of some common rheumatic diseases or syndromes. Scand. $j$. rheumatol. 3 (1974) 145-153.

2. ANDERSON, J. A. D. Rheumatism in in- dustry: A review. Br. j. ind. med. 28 (1971) 103-121.

3. BJELLE, A. Syndromes of reactive arthritides in Northern Sweden. In: DUMONDE D. C. and MAINI R. A. (eds.), Current research in rheumatoid arthritis and allied diseases. MTP Press Ltd., Lancaster, England. (in press)

4. BJELLE, A., HOFER, P. §. and SJÖSTRÖM, M. Myopathy of proximal muscles in arthritic patients. In: B. FELTKAMP (ed.), Non-articular forms of rheumatoid arthritis. Stafleus Scientific Publ. Co., Leiden 1977, pp. 129-140.

5. BOOTH, R. E. and MARVEL, J. P. Differential diagnosis of shoulder pain. Orthop. clin. north am. 6 (1975) 353-379.

6. CALLIET, R. Shoulder pain. F. A. Davis, Philadelphia, PA 1975. 115 p.

7. COVENTRY, M. B. Problems of painful shoulder. J. am. med. assoc. 151 (1953) $177-185$.

8. EKHOLM, I., HERBERTS, P., KADEFORS, R., LINDSTRÓM, I., MALMQVIST, R., PETERSEN, I. and ORTENGREN, R. Byggnadsarbeten med särskild ansträngning av skuldermusklerna. Läkartidningen 38 (1978) 3308-3314.

9. ENGDAL, S. Anthropometric measurements (Report 29). Swedish Furniture Research Institute, Stockholm 1974, pp. 8-9.

10. HERBERTS, P. and KADEFORS, R. A study of painful shoulder in welders. Acta orthop. scand. 47 (1976) 381-387.

11. HULT, L. Cervical, dorsal and lumbar spinal syndromes. Acta orthop. scand. (1954): suppl. $17,100 \mathrm{p}$.

12. JONSSON, B. and HAGBERG, M. The effect of different working heights on the deltoid muscle. Scand. j. rehabil. med. (1974): suppl. 3, 26-32.

13. MEULENGRACHT, E. and SCHWARTZ, M. Shoulder pain. Acta med. scand. 143 (1952) $350-360$

14. MINTER, W. T. III. The shoulder-hand syndrome in coronary disease. $J$. med. assoc. ga. 56 (1967) 45-49.

15. PEAT, M. and GRAHAME, R. E. Electromyographic analysis of soft tissue lesions affecting shoulder function. Am. $j$. phys. med. 56 (1977) 223-240.

16. SIMON, W. H. Soft tissue disorders of the shoulder. Orthop. clin. north am. 6 (1975) $521-539$.

17. STEINBROCKER, O. The painful shoulder. In: J. L. HOLLANDER (ed.), Arthritis and allied conditions. Lea and Phebiger, Philadelphia, PA 1972, pp. 1461-1502.

18. WIEDENBAUER, M. M. and MORTENSEN, O. A. An electromyographic study of the trapezius muscle. Am. j. phys. med. 31 (1952) $363-372$.

19. WRIGHT, V. and HAQ, A. M. MI. M. Periarthritis of the shoulder: I. Aetiological considerations with particular reference to personality factors. Ann. rheum. dis. 35 (1976) $213-226$. 